\title{
Effects of Arbuscular Mycorrhizal Fungi on the production of tomato in Togo
}

\author{
Essohouna Modom BANLA ${ }^{1}$, Agnassim BANITO $^{2 *}$ and Jean Mianikpo SOGBEDJI ${ }^{2}$ \\ ${ }^{1}$ Institut Togolais de Recherche Agronomique, BP 1163, Lomé, Togo. \\ ${ }^{2}$ Ecole Supérieure d'Agronomie, Université de Lomé, BP 1515, Lomé, Togo. \\ *Corresponding author; E-mail: bagnassim@hotmail.com; Tel. : +228-90033345/22254197
}

\begin{abstract}
A field study was conducted to assess the effectiveness of the Arbuscular Mycorrhizal Fungus (AMF) Glomus sp. on the plant growth, the flowering and the fruit yield of tomato (Lycopersicon esculentum, Mill.). Thus, 4 strains of Glomus sp. $\left(\mathrm{M}_{233}, \mathrm{M}_{353}, \mathrm{~B}_{3}\right.$ and $\left.\mathrm{Gd}\right)$ were tested in comparison with NPK fertilizer on 3 tomato varieties ICRIXINA, TROPIMECH and PETO76, using a complete randomized block design with three replications. The results revealed that 84 days after transplanting (DAT), the rate of root colonization by the fungus did not exceed $25 \%$, and the plant height was not affected by AMF inoculation, whereas $\mathrm{M}_{353}$ induced late flowering on ICRIXINA at 69 DAT and PETO76 at 74 DAT. Also the four AMF strains induced similar fruit yields as that of NPK for each of the 3 tomato varieties used. However, the response of tomato plants to AMF varied with the varieties.
\end{abstract}

(C) 2015 International Formulae Group. All rights reserved.

Keywords: AMF strains, effectiveness, tomato production, Togo.

\section{INTRODUCTION}

Tomato (Lycopersicon esculentum, Mill.) is one of the important vegetable crops worldwide with high nutritional value. Tomato World production estimated to 159023383 tons in 2011, has increased to 6968058 tones compared to previous year (FAO, 2012). In Togo, the area of tomato production in the urban and peri-urban zones increased while tomato yield decreased (Sikora and Fernandez, 2005). Production has decreased from 6000 to 5346 tones between 2010 and 2011 (FAO, 2012) due to many constraints, among which the decrease of soil fertility is one of the most important (James et al., 2005). To face this major constraint, farmers are used to apply chemical fertilizers which, however, are expensive and highly polluting.

One of the promising alternatives is the use of the arbuscular mycorrhizal fungi (AMF), which are organisms that build symbiotic relationship with more than $80 \%$ of living plants worldwide (Oehl et al., 2004; Smith and Read, 2008). AMF were reported to improve plant vigor and induce greater protection of the plant against various biotic and abiotic stress factors (Hol and Cook, 2005; Castillo et al., 2006; Khaosaad et al., 2007; Javaid and Riaz, 2008; Tchabi et al., 2008; Oseni et al., 2010). AMF induced more efficiency in nutrient and water acquisition, thus improved plant growth (Oseni et al., 2010), crop productivity (Javaid and Riaz, 
2008) and soil structure (Shreiner et al., 1997). Bryla and Koide (1990, 1998) reported significant increase of the number of flower and the number of mature fruits and their weights in mycorrhized tomatoes. They also found differential reaction of AMF among tomato genotypes. The effectiveness of AMF on the plant productivity has been well documented (Atimanav and Adholeya, 2002; Zaidi et al., 2003; Oseni et al., 2010). However, no data is available on the use of AMF in agriculture in Togo. Therefore, the present study aimed at investigating the effects of Arbuscular Mycorrhizal Fungi on the tomato production in Togo.

\section{MATERIALS AND METHODS \\ Experimental site}

The trial was conducted under field conditions at the High School of Agriculture Experimental Station at the University of Lomé in Togo, from May to September 2011 with the average temperature and relative humidity of $27{ }^{\circ} \mathrm{C}$ and $70 \%$, respectively, and the monthly average rainfall of $1000 \mathrm{~mm}$. The vegetation is a forest-savannah transition zone. The soil is sandy clayey with $48 \mathrm{ppm} P$, 0.08 meq K, 0.51 meq Ca, 0.39 meq $\mathrm{Mg}^{+}$, $0.06 \% \mathrm{~N}$ and $\mathrm{pH}$ of 7.73 .

\section{Inoculation of plants}

Three tomato varieties ICRIXINA, TROPIMECH and PETO76 and four strains of Glomus sp. $\left(\mathrm{M}_{233}\right.$, Gd from Benin, $\mathrm{M}_{353}, \mathrm{~B}_{3}$ from Senegal) were used. The plant material and the strains were received from International Institute of Tropical Agriculture (IITA) Station in Cotonou, Benin. The inoculums were grown on Allium porrum and applied at the dose of $2 \mathrm{~kg}$ per $0.5 \mathrm{~m}^{2}$ according to the method described by Mamathat and Bagyraj (2002) and Djigal (2003). The NPK fertilizer was applied 15 and 30 days after transplanting at the dose of 200 $\mathrm{g}$ per $3 \mathrm{~m}^{2}$.

\section{Experimental design}

Plants of tomato varieties ICRIXINA, TROPIMECH and PETO76 were grown for 3 weeks in a nursery on the soil previously sterilized at $105{ }^{\circ} \mathrm{C}$ for $30 \mathrm{~min}$ and inoculated with the mycorrhizal strains. Six treatments corresponding to 6 plots were adopted: one plot for each of the 4 mycorrhizal strains used, one plot for the NPK fertilizer, whereas the control was neither inoculated nor fertilized. Three weeks old seedlings were transplanted in the experimented field plots. The trial was set up as a complete randomized block design with three replications. Weeding was performed when necessary. Cypercal at the dose of 1 L.ha $^{-1}$ and Mancozeb at the dose of 0.75 kg.ha ${ }^{-1}$ were used to control leafborers and fungal diseases, respectively.

\section{Assessment of the mycorrhization}

Six randomly selected plants per plot were pulled out from the soil at 12 weeks after transplanting and washed. For each plant, 10 roots of $10 \mathrm{~mm}$ long stained with trypan blue in lactophenol using the method described by Phillips and Hayman (1970) amended by Brundrett et al. (1996). The mycorrhization rate was assessed using the grid line-intersect method of the later authors (Brundrett et al., 1996).

Assessment of the plant growth, early flowering and fruit yield

The plant height was recorded once a week from the $3^{\text {rd }}$ to the $12^{\text {th }}$ week after transplanting. The flowering of $50 \%$ of plants for each treatment was determined as an indicator of the early flowering. Tomato fruits were harvested three times a week on six plants per plot from 12 to 18 weeks after transplanting. The weight of the fruits per plant and the total yield were determined.

\section{Statistical analysis}

The recorded data analysis was performed using ANOVA in GenSTAT 
software. The means were discriminated using Duncan's Multiple Range Test at the level of $5 \%$.

\section{RESULTS}

\section{Rate of mycorrhization}

The results showed that the mycorrhization rates ranged from $6 \%$ to $23 \%$ among strains (Table 1). Significant differences of mycorrhization between the fungus strains were observed $(\mathrm{p}<0.001)$. The highest rate was recorded with plants inoculated with the strain $\mathrm{Gd}(23.67 \%)$ followed by that inoculated with the strain $\mathrm{M}_{353}(18 \%)$ on the variety ICRIXINA, while the strain $\mathrm{B}_{3}$ recorded the lowest mycorrhization level of $6.67 \%$ on the variety PETO76. The mycorrhization in all the inoculated plots was higher than in the NPK and the control plots. Also, significant differences of mycorrhization rates were observed regarding varieties $(p=0.004)$. For ICRIXINA the strain $\mathrm{Gd}$ induced a significantly higher mycorrhization level than $\mathrm{B}_{3}$ and $\mathrm{M}_{233}$, but did not differ from the strain $\mathrm{M}_{353}$. Also, on TROPIMECH, the strains Gd and $\mathrm{M}_{353}$ recorded statistically the same mycorrhization rate, but significantly higher than the strains $\mathrm{B}_{3}$ and $\mathrm{M}_{233}$. On PETO76 only the strain $\mathrm{M}_{353}$ induced a significantly higher mycorrhization rate than the strain $\mathrm{B}_{3}$.

Effects of AMF on plant growth, early flowering and fruit yield

Plant growth: The plant heights ranged from $55 \mathrm{~cm}$ to $77.67 \mathrm{~cm}$ for the 4 fungus strains, whereas the control plant heights were from $52.64 \mathrm{~cm}$ to $77.67 \mathrm{~cm}$ (Table 2). The ANOVA analysis revealed no significant difference between all the treatments including the NPK and the control $(p=0.69)$.

Flowering: The flowering time varied from 59 to 73 days after planting in inoculated plants and from 58 to 63 days in the control treatment (Table 3). However, no significant differences was observed between all the treatments, except the treatment with the strain $\mathbf{M}_{353}$ which induced a significantly longer flowering time than other treatments on the varieties ICRIXINA and PETO76 ( $\mathrm{p}=$ 0.002).

Fruit yield: On the variety ICRIXINA, the fruit yield was 10 t.ha $^{-1}$ for plot inoculated with $\mathrm{M}_{233}$ and $16 \mathrm{t}^{-h^{-1}}$ NPK for plot, respectively. On TROPIMECH the fertilizer NPK recorded the highest fruit yield of 26 t.ha ${ }^{-1}$ whereas the strain $\mathrm{M}_{233}$ as well as the control recorded 14 t.ha $^{-1}$. On the variety PETO76 the fertilizer NPK and the strain M233 recorded the fruit yield of $17 \mathrm{t} . h a^{-1}$, while the control recorded 12 t.ha $^{-1}$ (Table 4). The ANOVA analysis revealed generally no significant difference in fruit yield induced by the mycorrhizal strains and the NPK treatment, except for the strains M233 and B3 on the variety ICRIXINA and the strain M233 on the variety TROPIMECH where the fruit yield was significantly lesser than that of the NPK treatment $(\mathrm{p}=0.003)$.

Table 1: Rate of mycorrhization (\% of colonized roots).

\begin{tabular}{lccc}
\hline \multirow{2}{*}{ Treatments } & \multicolumn{3}{c}{ Varieties } \\
\cline { 2 - 4 } & ICRIXINA & TROPIMECH & PETO76 \\
\hline$M_{233}$ & $8.00 \mathrm{~cd}^{*}$ & $9.33 \mathrm{~b}$ & $9.33 \mathrm{ab}$ \\
$M_{353}$ & $18.00 \mathrm{ab}$ & $14.67 \mathrm{a}$ & $13.00 \mathrm{a}$ \\
$G d$ & $23.67 \mathrm{a}$ & $15.00 \mathrm{a}$ & $12.33 \mathrm{ab}$ \\
$B_{3}$ & $11.33 \mathrm{bc}$ & $8.00 \mathrm{~b}$ & $6.67 \mathrm{bc}$ \\
$N P K$ & $3.63 \mathrm{~d}$ & $2.33 \mathrm{c}$ & $2.00 \mathrm{c}$ \\
Control & $2.33 \mathrm{~d}$ & $1.33 \mathrm{c}$ & $2.33 \mathrm{c}$ \\
\hline *In a column values with the same letter are not significantly different at 5\% level with Duncan's Multiple Range \\
Test. M233, M353, B3 and Gd = Glomus strains used.
\end{tabular}


Table 2: Average tomato plant height $(\mathrm{cm})$.

\begin{tabular}{lccc}
\hline Treatments & \multicolumn{3}{c}{ Varieties } \\
\cline { 2 - 4 } & ICRIXINA & TROPIMECH & PETO76 \\
\hline$M_{233}$ & $55.00 \mathrm{a}^{*}$ & $67.00 \mathrm{a}$ & $77.67 \mathrm{a}$ \\
$M_{353}$ & $57.00 \mathrm{a}$ & $66.33 \mathrm{a}$ & $76.00 \mathrm{a}$ \\
$G d$ & $56.00 \mathrm{a}$ & $65.67 \mathrm{a}$ & $74.67 \mathrm{a}$ \\
$B_{3}$ & $56.67 \mathrm{a}$ & $65.67 \mathrm{a}$ & $75.67 \mathrm{a}$ \\
$N P K$ & $52.64 \mathrm{a}$ & $64.00 \mathrm{a}$ & $77.67 \mathrm{a}$ \\
Control & $56.33 \mathrm{a}$ & $63.00 \mathrm{a}$ & $73.67 \mathrm{a}$ \\
\hline
\end{tabular}

* In a column values with the same letter are not significantly different at 5\% level with Duncan's Multiple Range Test. M233, M353, B3 and Gd = Glomus strains used.

Table 3: Time of flowering of tomato (in days after planting).

\begin{tabular}{lcll}
\hline \multirow{2}{*}{ Treatments } & \multicolumn{3}{c}{ Varieties } \\
\cline { 2 - 4 } & ICRIXINA & TROPIMECH & PETO76 \\
\hline$M_{233}$ & $59.33 \mathrm{c}^{*}$ & $59.67 \mathrm{a}$ & $62.00 \mathrm{~b}$ \\
$M_{353}$ & $68.67 \mathrm{a}$ & $58.67 \mathrm{a}$ & $73.33 \mathrm{a}$ \\
$G d$ & $63.00 \mathrm{bc}$ & $58.67 \mathrm{a}$ & $64.33 \mathrm{~b}$ \\
$B_{3}$ & $66.67 \mathrm{ab}$ & $59.33 \mathrm{a}$ & $62.00 \mathrm{~b}$ \\
$N P K$ & $61.33 \mathrm{bc}$ & $59.67 \mathrm{a}$ & $62.00 \mathrm{~b}$ \\
Control & $58.33 \mathrm{c}$ & $61.00 \mathrm{a}$ & $62.61 \mathrm{~b}$ \\
\hline
\end{tabular}

*In a column values with the same letter are not significantly different at 5\% level with Duncan's Multiple Range Test. M233, M353, B3 and Gd = Glomus strains used.

Table 4: Tomato fruit yield $\left(\mathrm{t} \cdot \mathrm{ha}^{-1}\right)$.

\begin{tabular}{|c|c|c|c|c|}
\hline \multirow[t]{2}{*}{ Treatments } & \multicolumn{4}{|c|}{ Varieties } \\
\hline & ICRIXINA & TROPIMECH & PETO76 & \\
\hline$M_{233}$ & $10.01 \mathrm{~b}^{*}$ & $14.45 \mathrm{~b}$ & 16.63 & $\bar{i}$ \\
\hline$M_{353}$ & $14.63 \mathrm{ab}$ & $22.62 \mathrm{a}$ & 13.38 & 1 \\
\hline$G d$ & $12.34 \mathrm{ab}$ & $25.34 \mathrm{a}$ & 14.22 & 1 \\
\hline$B_{3}$ & $6.69 \mathrm{~b}$ & $23.43 \mathrm{a}$ & 15.68 & 1 \\
\hline$N P K$ & $16.38 \mathrm{a}$ & $26.16 \mathrm{a}$ & 17.00 & : \\
\hline Control & $11.16 \mathrm{~b}$ & $14.38 \mathrm{~b}$ & 12.11 & 1 \\
\hline
\end{tabular}




\section{DISCUSSION}

Previous experiment on the colonization of tomato plants by Glomus sp. revealed a mycorrhization rate of higher than $50 \%$ (Nedorost and Pokluda, 2012). In the present study, the colonization level did not exceed 24\%. Low mycorrhizal root colonization in field (10-20\%) has also been observed by Ashley (2007). The author found that low seedlings mycorrhizal colonization before transplanting and soil disturbance during production were correlated with low mycorrhizal root colonization in field. In the present study, the seedlings have been transplanted only 21 days after sowing; also weeding has been performed 10 times during the experiment. This might disturb the soil and influence negatively the establishment of the fungus on the tomato roots. Earlier studies conducted by Evans and Miller (1990), demonstrated that the disturbance of the soil induced destruction of the AMF mycelium and led on the reduction of the colonization of maize plants by the fungus. The present study revealed a variability mycorrhization in the rate between fungus strains and also between tomato varieties. Recently, Castillo et al. (2012) found also difference in AMF colonization of wheat, barley and oats varieties in southern Chile.

The absence of an AMF effect on vegetative growth of tomato plants was reported by Smith et al. (2004) and Ashley (2007) who found no response of the plants growth to AMF colonization. The authors suggested that the unresponsive of the plants growth could be due to the low rate of AMF mycorrhization observed. Moore (1998) observed that less than $20 \%$ of root colonization by the AMF did not induce positive effect on the plant growth. In the present study, the rates of mycorrhization obtained were generally less than $20 \%$, thus could explain the none effect on the plant growth observed.

Nowak (2004) observed that tomato plants inoculated with some Glomus species had a late flowering compared to none inoculated plants. Poulton et al. (2002) found that AMF colonization reduced significantly the flowering time of the plants. Recently, Salvioli et al. (2012) found also that the mycorrhization of Glomus mosseae strains on tomato plants reduced significantly their flowering time. In spite of that these authors experimented under controlled conditions while the present study was carried out under field conditions with natural climate condition, ssimilar results were found. This could explain the ineffectiveness of the mycorrhization on the flowering time. The results showed significant effect on flowering time induced by the strain $\mathrm{M}_{353}$ on the varieties ICRIXINA and PETO76 but not on TROPIMECH. Variability of the mycorrhizal response on the flowering of tomato plants has been demonstrated by Poulton et al. (2002).

The effect of AMF on tomato yield is remarkable. Except plots inoculated with the strain $\mathrm{M}_{233}$ on varieties ICRIXINA and TROPIMECH, and those inoculated with the strain $\mathrm{B}_{3}$ on ICRIXINA, all inoculated plots recorded statistically the same tomato yield as NPK treatment. Former studies demonstrated the capacity of the AMF to improve water and mineral supply of tomato plants in the absence of NPK, thus to induce the vegetable yield as well as the mineral fertilizer (Busher, 2007). The author observed that the Glomus AMF improved plant supply in water, phosphorus and nitrogen, leading to a higher yield. Also, Oseni et al. (2010) demonstrated an enhancement of the crop productivity due to inoculation with the AMF. Mycorrhizal fungi have been reported in the roots of chickpea plants, improving the growth and yield of these plants (Zaidi et al., 2003). Earlier studies reported the enhancement of growth of leguminous plants by the AMF (Atimanav and Adholeya, 2002). The present results revealed differential reaction of the strains $B_{3}$ and $M_{233}$ on the tomato yield of the varieties. Poulton et al. (2002) showed that the response of tomato plants to AMF inoculation varied with genotypes. In the present study, differential reaction of the varieties ICRIXINA and TROPIMECH in fruit yield after inoculation with the strains $B_{3}$ and $M_{233}$ was observed. 


\section{Conclusion}

The goal of this study was to contribute to the improvement of tomato production by the use of the mycorrhizal fungi Glomus sp. Then, four strains were tested on three tomato varieties and the parameters such as mycorrhizal root colonization, plant growth, flowering and fruit yield were recorded. The results showed that even low, mycorrhization of the tomato plants roots was established. Also, the fungi induced significant fruit yield, however the effects on the fruit yield varied with the strains and the tomato varieties.

\section{REFERENCES}

Atimanav G, Adholeya A. 2002. AM inoculations of five tropical fodder crops and inoculum production in marginal soil amended with organic matter. Biol. Fertil. Soil, 35: 214-218.

Brundrett M, Bougher N, Dell B, Grove T, Malajezuk N. 1996. Working with Mycorrhizas in Forestery and Agriculture. ACIAR Monograph 32, 374 p.

Bryla DR, Koide RT. 1990. Regulation of reproduction in wild and cultivated Lycopersicon esculentum Mill. by vesicular-arbuscular mycorrhizal infection. Oecologia, 84: 74-81.

Bryla DR, Koide RT. 1998. Mycorrhizal response of two tomato genotypes relates to their ability to acquire and utilize phosphorus. Ann. Bot., 82: 849-857.

Bucher M. 2007. Functional biology of plant phosphate uptake at root and mycorrhiza interfaces. New Phytologist, 173: 11-26.

Castillo CG, Puccio F, Morales D, Borie F, Sieverding E. 2012. Early arbuscular mycorrhiza colonization of wheat, barley and oats in Andosols of southern Chile. J. Soil Sci. Plant Nutr., 12(3): 511-524.

Castillo P, Nico AI, Azcón-Aguilar C, Del Río Rincón C, Calvet C, Jiménez-Díaz RM. 2006. Protection of olive planting stocks against parasitism of root-knot nematodes by arbuscular mycorrhizal fungi. Plant Pathol., 55: 705-713.
Djigal D. 2003. Interactions entre la communauté microbienne du sol (bactéries et champignons mycorhiziens) et les nématodes bactérivores: effet sur la nutrition minérale et la croissance de différentes plantes. Thèse de doctorat, Université Cheikh Anta Diop de Dakar. $166 \mathrm{p}$.

FAO. 2012. Food and Agriculture Organization Statistic Data 2011 of the United Nation. http://www.fao.org/ docrep/T1696E/t1696e07.htm.

Hol WHG, Cook R. 2005. An overview of arbuscular mycorrhizal fungi-nematode interactions. Basic Appl. Ecol., 6: 489503.

James B, Godonou I, Atcha C, Baimey H. 2006. Healthy vegetables through participatory IPM in peri-urban areas of Benin. Summary of activities and achievements, 2003-2006. IITA Benin, $134 \mathrm{p}$.

Javaid A, Riaz T. 2008. Micorhizal colonization in different varieties of Gladiolus and its relation with plant vegetative and reproductive growth. Intern. J. Agr. Biol., 10: 278-282.

Khaosaad T, Garcia-Garrido, Steinkellner S, Vierlheilig H. 2007. Tale-all disease is systematically reduced in roots of mycorrhizal barley plants. Soil Biol. Bioch., 39: 727-734.

Mamatha G, Bagyaraj DJ. 2002. Different levels of VAM inoculums application on growth and nutrition of tomato in the nursery. In: Reddy SM, Reddy SR, Singarachary MA, Grisham S, eds. Bioinoculants for suitainable Agriculture and Forestery. Proc. Nat. symp. Feb. 1618, 2001, Jodphur, India: Scientific Publishers.

Moore JC. 1998. Plant succession in semi-arid grasslands and response to mycorrhizal colonization. Abstracts Ecological Society of America Meeting, Davis, CA, USA, Morton et Walker, 12: 176-189.

Nedorost L, Pokluda R. 2012. Effect of arbuscular mycorrhizal fungi on tomato yield and nutrient uptake under different 
fertilization levels. Acta Univ. Agr. Silv. Mend. Brun., 8: 181-186.

Netscher C, Sikora RA. 1990. Nematode parasites of vegetables, In Plant Parasitic Nematodes in Subtropical and Tropical Agriculture, Luc M, Sikora RA, Bridge $\mathrm{J}$ (eds). CAB International: Wallingford, UK, 237-283.

Nowak J. 2004. Effects of arbuscular Mycorrizal Fungi and organic fertilization on growth, flowering, nutrient uptake, photosynthesis and transpiration of tomato (Lycopersicum esculentum, Mill. Bailey 'Tango Orange'. Symbiosis, 37: 259-266.

Oehl F, Sieverding E, Mäder P, Dubois D, Ineichen K, Boller T, Wiemken A. 2004. Impact of long-term conventional and organic farming on the diversity of arbuscular mycorrhizal fungi. Oecologia, 138: $574-583$.

Osseni TO, Shongwe NS, Masarirambi MT. 2010. Effect of arbuscular mycorrhizal (AM) inoculation on the performance on the tomato nursery seedling in vermiculite. Intern. J. Agr. Biol., 12: 789-792.

Phillips JM, Hayman PS. 1970. Improved procedure for clearing roots and staining parasitic and vesicular-arbuscular mycorrhizal fungi for rapid assessment of infection. Trans. Brit. Micol. Soc., 55: 158-161.

Poulsen KH, Nagy R, Gao L-L, Smith SE, Busher M, Smith FA, Jakobsen I. 2005. Physiological and molecular evidence for Pi uptake via the symbiosic pathway in a reduced mycorrhizal colonization mutant in tomato associated with a compatible fungus, New Phytologist, 168: $445-454$.

Poulton JL, Koide RT, Stephenson AG. 2001. Effects of mycorrhizal infection, soil phosphorus availability improve vegetative growth and the female and male functions in tomato. New Phytologist, 154: 255-264.
Poulton JL, Koide RT, Stephenson AG. 2001. Effect of mycorrhizal infection and high soil phosphorus improve vegetative growth and the female and male functions in tomato. New Phytologist, 154: 255-264.

Ryan MH, van Herwaarden AF, Angus JF, Kirkegaard JA. 2005. Reduced growth of autumn-sown wheat in a low-P soil is associated with high colonization by arbuscular mycorrhizal fungi. Plant and Soil, 270: 275-286.

Salvioli A, Zouari I, Chalot M, Bonfante P. 2012. The arbuscular mycorrhizal status has an impact on the transcriptome profile and amino acid composition of tomato fruit. BMC Plant Biol., 12. DOI : 10.1186/1471-2229-12-44.

Shreiner RP, Mihara KL, MC Daniel H, Bethlenfalvay GJ. 1997. Mycorrhizal fungi influence plant and soil functions and interactions. Plant and Soil, 188: 199-209.

Sikora RA, Fernandez E. 2005. Nematodes parasites of vegetables. In PlantParasitic Nematodes in Subtropical and Tropical Agriculture ( $2^{\text {nd }}$ edn), Luc M, Sikora, RA, Bridge J (eds). CABI Publishing: Wallingford, UK, 1230; 319392.

Smith SE, Read DJ. 2008. Mycorrhizal Symbiosis (3rd edn). Academic Press: San Diego.

Smith SE, Smith FA, Jakobsen I. 2004. Functional diversity in arbuscular mycorrhizal (AM) symbiosis: the contribution of the mycorrhizal $\mathrm{P}$ uptake pathway is not correlated with mycorrhizal responses in growth or total P uptake, New Phytologist, 162: 511524.

Zaidi A, Khan MS, Amil M. 2003. Interactive effect of rhizotrophic micro organisms on yield and nutrient uptake of chickpea (Cicer arietinum L.). Eur. J. Agron., 19(1): 15-21. 